\title{
IN SILICO MOLECULAR PROPERTIES PREDICTION OF COMPOUNDS FROM CARICA PAPAYA LEAF EXTRACT
}

\begin{abstract}
ABHIGNA NARA ${ }^{1}$, KUDAGI BL ${ }^{2}$, SUBASH KR ${ }^{3}$, SRIHARSHA RAYAM ${ }^{2}$
${ }^{1}$ Department of Pharmacology, Narayana Medical College and Research Institute, Nellore, Andhra Pradesh, India. ${ }^{2}$ Department of Pharmacology, Narayana Medical College and Research Institute, Nellore, Andhra Pradesh, India. ${ }^{3}$ Department of Pharmacology, Sri Venkateswara Institute of Medical Sciences -SPMC(W), Tirupati, Andhra Pradesh, India. Email: abhignanara409@gmail.com
\end{abstract}

Received: 03 August 2020, Revised and Accepted: 03 September 2020

ABSTRACT

Objectives: The objectives of the study were to analyze the scientific rationale and possible pharmacokinetic properties of certain biologically active compounds from Carica papaya leaf extract in silico.

Methods: This study was investigated on web-based tools PUBCHEM to extract the chemical structure followed by authentication and validation with chemical formula. The 2-dimensional structures are further converted to 3-dimensional (3D) structure with CHEMSKETCH software, the derived 3D structures are then screened for molecular properties and druglikeness score followed by absorption, distribution, metabolism, elimination, and toxicity through admetSAR software. The reports are analyzed and predicted for possible drug like compound in leaf extract of papaya.

Results: The results obtained indicate that the compounds screened papain, chymopapain, quercetin, and protocatechuic acid had the druglikeness score $-0.93,-0.05,+0.93$, and +0.74 , respectively. On acute toxicity prediction, quercetin belonged to Class II and other compounds belonged to Class III.

Conclusion: The study confirms the among the compounds screened for in silico druglikeness and adsorption, distribution, metabolism, excretion, and toxicity profile quercetin a flavonoid can be possibly developed as effective anti-dengue compound.

Keywords: Carica papaya, In silico, Pharmacokinetics, Toxicology.

(C) 2020 The Authors. Published by Innovare Academic Sciences Pvt Ltd. This is an open access article under the CC BY license (http://creativecommons. org/licenses/by/4. 0/) DOI: http://dx.doi.org/10.22159/ajpcr.2020.v13i11.39297

\section{INTRODUCTION}

Carica papaya plant product extract contains many chemical constituents among which two important biologically active compounds, namely, chymopapain and papain are nowadays used for digestive disorders [1]. The papain, caricain, chymopapain, and glycine endopeptidase derived from $C$. papaya can improve gastrointestinal tract acidic $\mathrm{pH}$ condition and pepsin degradation. Few other active compounds of C. papaya considered as a "naturally immobilized" biocatalyst are lipase, a hydrolase found in water-insoluble fraction of crude papain [2]. In folklore medicine, the white papaya latex is used to treat dyspepsia and topically applied for external burns and scalds. The seeds and fruits of C. papaya are shade dried and powdered and used as antihelminthic as well as anti-amebic [3]. Dried and pulverized leaves decoction is administered as a purgative for horses and used for the treatment of infections of genitourinary system. The unripe and semi-ripe $C$. papaya fruits are ingested or applied on the cervix as folklore treatment to cause abortion. However, the consumption of unripe and semi-ripe papaya fruits could be unsafe during pregnancy, but consumption of ripe fruits during pregnancy causes no risk [4]. The chemical constituents individually though isolated and reported in various journals, but still individually many of these C. papaya compounds have not been studied for drug-like properties.

In silico computer simulation is considered as one of the most efficient ways to achieve reduction of financial burden in research, refinement, and replacement of animals in research [5]. In silico computer simulation of research can provide predictive results of numerous compounds of more complex phenomena for which limited or no data are available in short span of time, thereby a lead compound with high success rate can more easily be selected for further research. Hence, the current study is an attempt in search of preferred drug-like compounds from C. papaya leaf extract by computer simulation and an attempt to evaluate the lead compound with possible better therapeutic activity for further wet laboratory analysis. Hence, as a preliminary step, the present study is to analyze adsorption, distribution, metabolism excretion, and toxicity (ADME\&T) properties of biologically active compounds from C. papaya leaf extract in silico.

\section{MATERIALS AND METHODS}

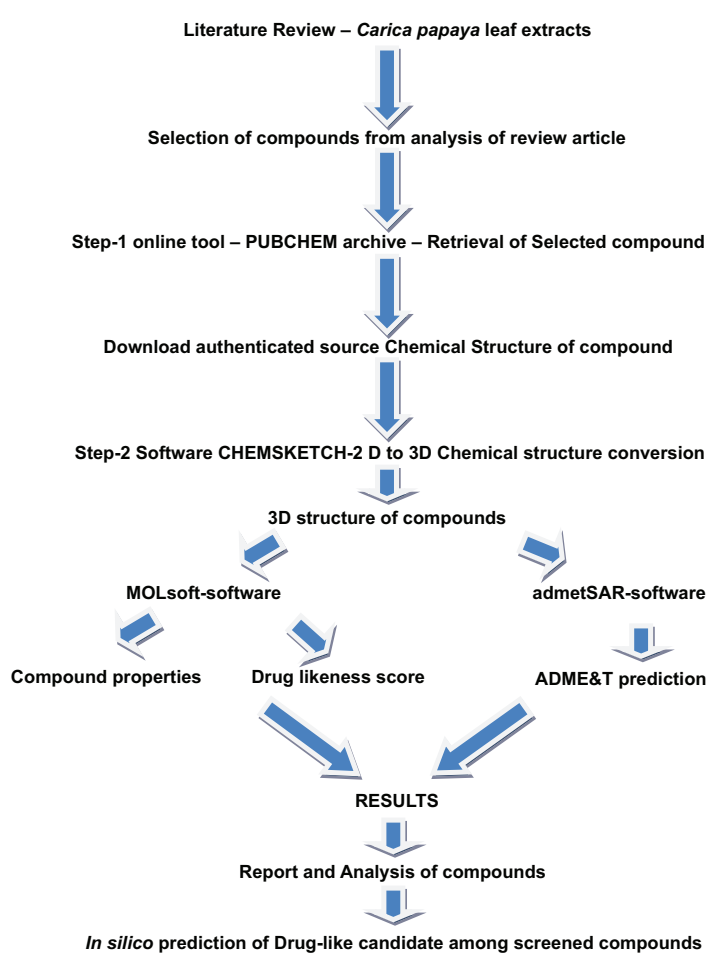




\section{Hardware and Software}

The selected compounds molecular properties of chemical structure from leaf extract of C. papaya extract are carried out in Hewlett Packard 2016 Model installed with Windows 11 software, Java enabled with updated plugins.

\section{Data Set}

The selected compound chemical structures of $C$. papaya with 2-dimensional (2D) pictures were collected from accredited indexed published journal and other sources such as PubChem, Chembank, ChemPDB, and Asinex Ltd. After detailed review, the structures are drawn with ChemSketch followed by PHASE software module was used to convert the 2D structures into 3-dimensional (3D) structures [6].

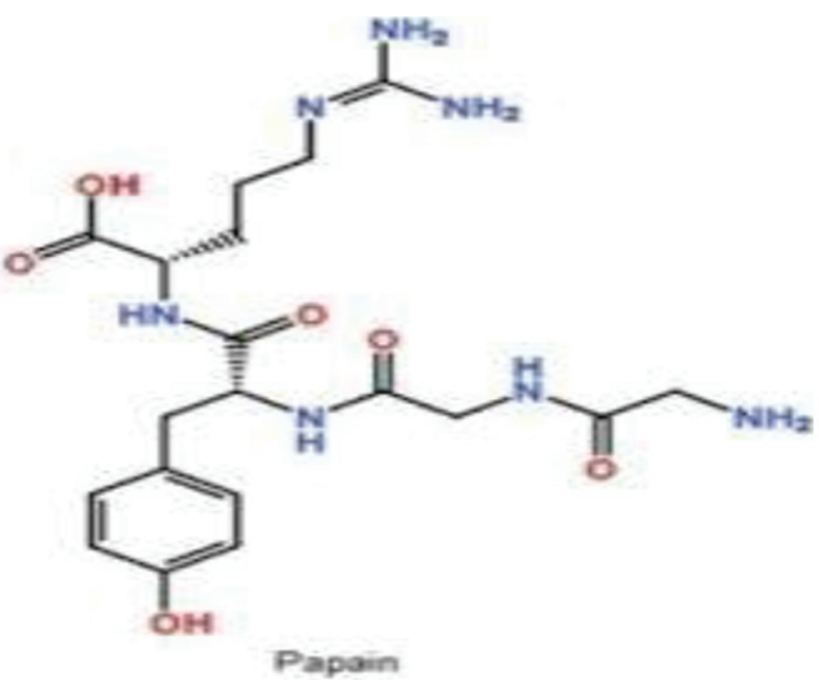

Fig. 1: Two-dimensional chemical structure of papain

\section{Virtual screening}

ADMET predictions

The 3D structures created will be used for ADMET predictions by admetSAR version 2.0. In silico results of compounds on absorption, distribution, metabolism, excretion, and toxicity are acquired in the virtual screening workflow protocol, followed by a web-based tool MOLSOFT L.L.C was used to run the molecular properties evaluation and druglikeness score $[7,8]$.

\section{Statistical methods and calculation}

Calculation of molecular volume and druglikeness score is done using an interactive Molecular Properties Calculator applet (MolSoft L.L.C., San Diego, CA, USA). The study is done in the department of pharmacology and college library using online tools during July 2018-August 2018. Since the study does not involve animal and humans, exemption certificate from the Institutional Ethics Committee is obtained before initiating the study.

\section{RESULTS AND DISCUSSION}

C. papaya is an herbaceous plant known for cultivation for the production of papaya fruit. C. papaya leaf juice is used as an herb by Ayurvedic and Siddha systems of medicine [9]. The leaf extract preparation is used for the treatment of various ailments such as fever, inflammation, diabetes, and wound dressing [10]. Lately, Central Council for Research in Siddha has published a guideline on use of papaya leaf extract juice for Siddha practices for clinical management of dengue fever [11]. This has led to commercial production and wide use of papaya leaf extract in tablet forms as over-the-counter successful product against dengue. The plant leaf extract has many constituents and it's a challenge to identify, isolate the active principle responsible for medicinal activity. The present study by in silico experimental tools on human models analyzed molecular properties, ADMET, and predicted druglikeness of various constituents of papaya leaf extract which includes papain, chymopapain, quercetin, and protocatechuic acid.

The present study is designed to study and analyze the ADME\&T properties followed by prediction of drug-like compound based on
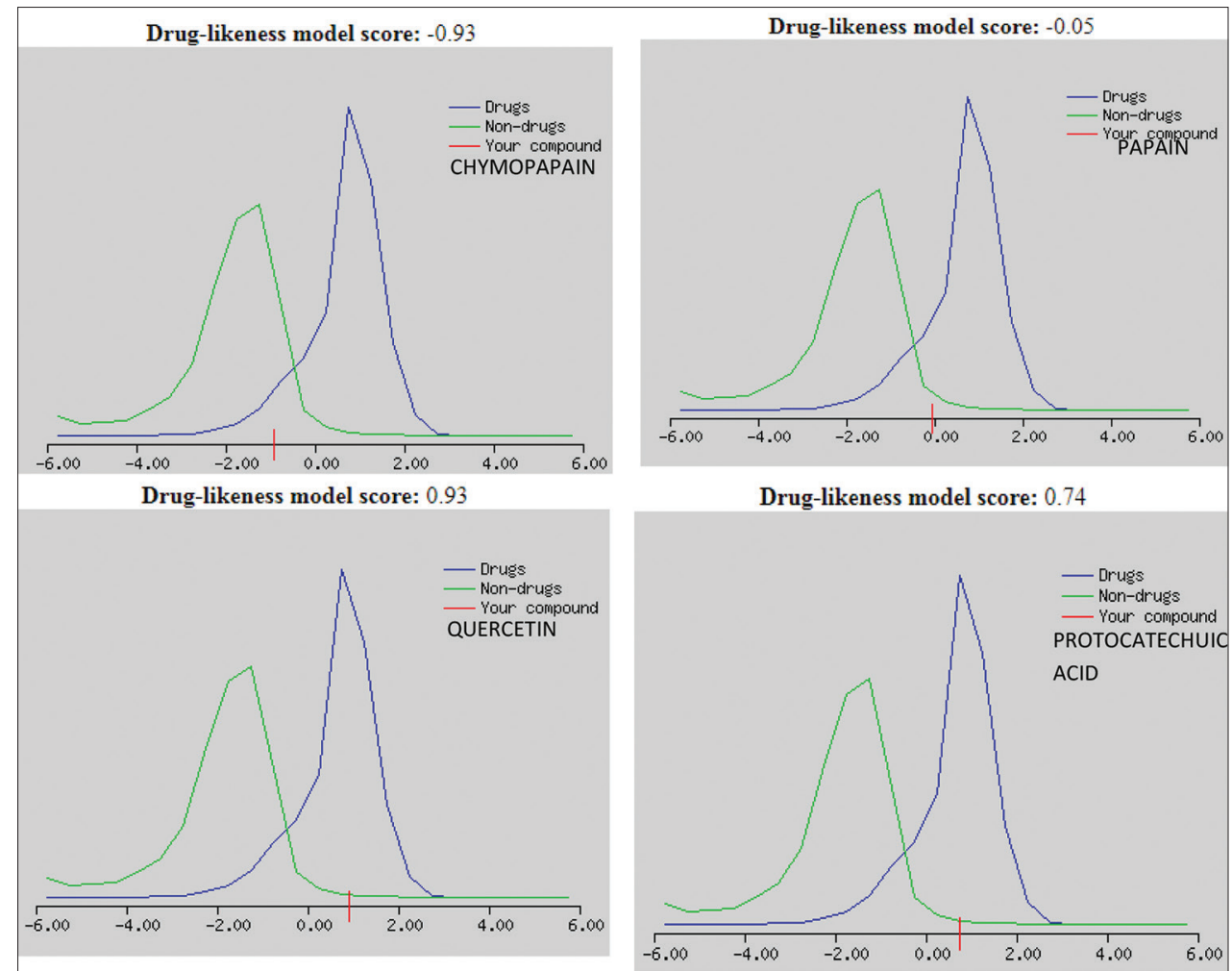

Fig. 2: Druglikeness model scoring of compounds. (a) Chymopapain, (b) papain, (c) quercetin, (d) protocatechuic acid 
results obtained by in silico experimental models. The project was initiated after taking approval letter from the Institutional Ethics Committee on July 2018. The research was done in the department of pharmacology for a period of 25 days in the month of July 2018 to August 2018 followed by analysis and interpretation of results.

From the detailed review of literature from earlier studies, papain, chymopapain, quercetin, and protocatechuic acid 2D chemical structure were retrieved from PUBCHEM online compound database platform, all the four compounds were available with PubChem I.D for authentication and verification and successfully 2D structures converted to 3D structure by CHEMSKETCH software (Table 1), the 3D structures are the processed with MOLSOFT L.L.C software and the molecular properties are predicted (Table 2). The analysis of result for molecular properties revealed that the octanol-water partition coefficient values of quercetin (1.5) and protocatechuic acid (0.93) were more compared with papain (-4) and chymopapain (-2) and predicted to have better water solubility of compound (Fig. 1 and 2). Among the four compounds, the hydrogen bond donor and acceptor quercetin had higher values are predicted to have better chance of getting docked to receptors as ligand (Table 2). From the analyzed report and by the structures when subjected to in silico druglikeness model, quercetin and protocatechuic acid had better scores +0.93 and +0.74 , thereby correlating with molecular properties, quercetin was predicted as possible drug-like candidate among the screened compounds.

The ADME\&T human model prediction by admetSAR software of the four compounds 3D structures was analyzed. The absorption model predicted papain and quercetin had human intestinal absorption, whereas chymopapain and protocatechuic acid had both human oral and intestinal absorption. The distribution model (Table 3) predicted all the compounds had $<2 \%$ plasma protein binding (PPB), none of

Table 1: 2-dimensional structures to 3-dimensional structure conversion with ChemSketch software

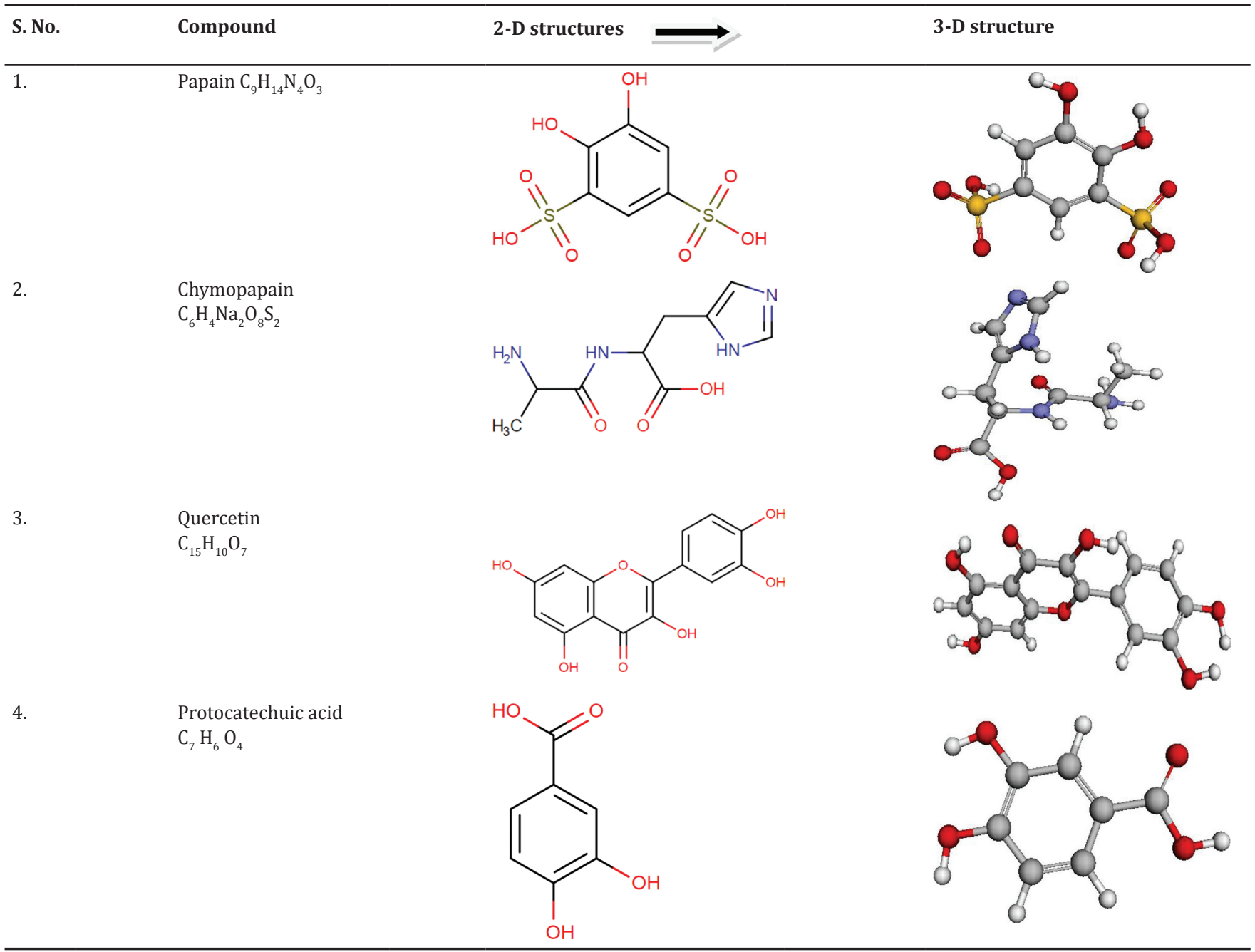

Table 2: Molecular properties and druglikeness of $C$. papaya leaf extract active compounds

\begin{tabular}{|c|c|c|c|c|c|c|c|}
\hline S. No. & Compounds & $\begin{array}{l}\text { PubChem } \\
\text { CID }\end{array}$ & $\begin{array}{l}\text { Molecular } \\
\text { weight }(\mathrm{g} / \mathrm{mol})\end{array}$ & $\begin{array}{l}\text { LogP (Octanol-water } \\
\text { partition coefficient value) }\end{array}$ & H-bond donor & $\begin{array}{l}\text { H-bond } \\
\text { acceptor }\end{array}$ & $\begin{array}{l}\text { Druglikeness } \\
\text { score }\end{array}$ \\
\hline 1. & Papain $\mathrm{C}_{9} \mathrm{H}_{14} \mathrm{~N}_{4} \mathrm{O}_{3}$ & 9369 & 226.236 & -4 & 4 & 5 & -0.93 \\
\hline 2. & Chymopapain & 9001 & 314.19 & -2 & 2 & 8 & -0.05 \\
\hline $\begin{array}{l}3 . \\
4 .\end{array}$ & $\begin{array}{l}\mathrm{C}_{6} \mathrm{H}_{4} \mathrm{Na}_{2} \mathrm{O}_{8} \mathrm{~S}_{2} \\
\text { Quercetin } \mathrm{C}_{15} \mathrm{H}_{10} \mathrm{O}_{7} \\
\text { Protocatechuic acidC } \mathrm{H}_{6} \mathrm{O}_{4}\end{array}$ & $\begin{array}{l}5280343 \\
72\end{array}$ & $\begin{array}{l}302.238 \\
154.03\end{array}$ & $\begin{array}{l}1.5 \\
0.93\end{array}$ & $\begin{array}{l}5 \\
3\end{array}$ & $\begin{array}{l}7 \\
4\end{array}$ & $\begin{array}{l}+0.93 \\
+0.74\end{array}$ \\
\hline
\end{tabular}

CID-compound index, H-hydrogen. C. papaya: Carica papaya 
Table 3: ADMET predicted profile of $C$. papaya leaf extract compounds

\begin{tabular}{|c|c|c|c|c|c|}
\hline \multirow[t]{2}{*}{ S. No. } & \multirow[t]{2}{*}{ Compounds } & \multicolumn{4}{|l|}{ Absorption } \\
\hline & & HIA & НОВ & $\mathrm{CaCO}_{2}$ & \\
\hline 1. & Papain & + & - & - & \\
\hline 2. & Chymopapain & + & + & - & \\
\hline 3. & Quercetin & + & _- & - & \\
\hline 4. & Protocatechuic acid & + & + & & \\
\hline \multirow[t]{2}{*}{ S. No. } & Compounds & \multicolumn{4}{|l|}{ Distribution } \\
\hline & & PPB $100 \%$ & Pgp substrate & Pgp inhibitor & BBB \\
\hline 1. & Papain & 0.581 & - & - & + \\
\hline 2. & Chymopapain & 0.744 & - & - & + \\
\hline 3. & Quercetin & 1.175 & - & - & - \\
\hline 4. & Protocatechuic acid & 0.717 & - & - & - \\
\hline \multirow[t]{2}{*}{ S. No. } & Compounds & \multicolumn{2}{|l|}{ Metabolism } & \multicolumn{2}{|l|}{ Excretion } \\
\hline & & CYP 450 substrate & CYP 450 inhibitor & Plasma t1/2 & Renal clearance \\
\hline 1. & Papain & + & - & NP & NP \\
\hline 2. & Chymopapain & + & + & NP & NP \\
\hline 3. & Quercetin & + & - & NP & NP \\
\hline 4. & Protocatechuic acid & + & + & NP & NP \\
\hline
\end{tabular}

HIA: Human intestinal absorption, HOA: Human oral bioavailability, PPB: Plasma protein binding, Pgp-P glycoprotein, BBB: Blood-brain barrier, CYP: Cytochrome, NP: Not predictable. C. papaya: Carica papaya, ADMET: Adsorption, distribution, metabolism, excretion, and toxicity

Table 4: Toxicology prediction profile of $C$. papaya leaf extract compounds

\begin{tabular}{lllll}
\hline S. No. & Compounds & Toxicity & & Acute oral toxicity (Class) \\
\cline { 3 - 5 } & & Hepatotoxicity & Ames test & III \\
\hline 1. & Papain & + & - & III \\
2. & Chymopapain & + & + & II \\
3. & Quercetin & + & - & III \\
4. & Protocatechuic acid & - & &
\end{tabular}

the screened compounds are $\mathrm{P}$ glycoprotein substrate or inhibitor and with blood-brain barrier (BBB) model, papain and chymopapain were predicted to cross BBB. Based on poor PPB of $<2 \%$ capacity of drugs, it was analyzed that all compounds have wider distribution. The metabolism model predicted all compounds are substrate of CYP450 and chymopapain and protocatechuic acid is enzyme CYP450 inhibitor. CYP 450 is one of the major enzymes responsible for metabolism and if inhibited the possibilities of drug-drug interaction side effects were predicted to be high. The elimination model has failed to predict the plasma $\mathrm{t} 1 / 2$ and renal clearance of the drug.

The toxicity model (Table 4) predicted protocatechuic acid to fall under Class III for acute oral toxicity testing and appeared safer with no hepatotoxicity and test negative for AMES. Quercetin is Class II which is positive prediction for hepatotoxicity and AMES model.

The advantage of in silico experimentation method is, a large number of molecules can be screened and predicted in short duration with minimal financial and human hours. The use of animals in preliminary screening can be largely reduced and by this experimental procedure no animals and humans are harmed.

Among the four compounds screened, quercetin and protocatechuic acid have preferred molecular properties and drug-like features. Quercetin a flavonoid is reported to have significant antiviral activity on dengue virus by in vitro testing methods [12]. There are published research articles that $C$. papaya leaf extract increased 12-lipoxygenase and platelet-activating factor receptor gene expression [13]. The in silico prediction data from the present study can be applied for further research on quercetin and protocatechuic acid by wet laboratory studies on above said pathways to identify platelet production stimulation ability of the compound in treatment and management of dengue infection.

\section{CONCLUSION}

The present study selected four compounds based on extensive review of literature papain, chymopapain, quercetin, and protocatechuic acid. On the whole based on molecular properties, druglikeness score, and ADME\&T model, this study concludes that quercetin and protocatechuic acid are predicted to have better drug-like features and protocatechuic acid from the papaya leaf extract had better toxicity profile.

\section{ACKNOWLEDGMENT}

Our sincere thanks to Narayana Medical College for academic support, and SVIMS - Department of Pharmacology for the technical guidance given to us.

\section{AUTHORS' CONTRIBUTIONS}

Abhigna Nara played a key role as principal investigator including drafting the proposal acquiring approval and funding from ICMR-STS Project. B.L Kudagi played a crucial role in reviewing the proposal and final approval including drafting and reviewing before and after completion of project for approval to publication. K.R.Subash contribution was toward data procurement and analysis. Sriharsha Rayam contributed as coguide for the study including drafting the article, reviewing content, final endorsement of the version to be published, and agreed to be accountable for all perspectives of the work

\section{CONFLICTS OF INTEREST}

The author declared that there are no conflicts of interest related to this study. 


\section{FUNDING}

The author gratefully acknowledges ICMR-STS for funding for this work.

\section{REFERENCES}

1. Huet J, Looze Y, Bartik K, Raussens V, Wintjens R, Boussard P. Structural characterization of the papaya cysteine proteinases at low pH. Biochem Biophys Res Commun 2006;341:620-6.

2. de Maria PD, Sinisterra JV, Tsai SW, Alcantara AR. Carica papaya lipase (CPL): An emerging and versatile biocatalyst. Biotechnol Adv 2006;24:493-9.

3. Okeniyi JA, Ogunlesi TA, Oyelami OA, Adeyemi LA. Effectiveness of dried Carica papaya seeds against human intestinal parasitosis: A pilot study. J Med Food 2007;10:194-6.

4. Adebowale A, Garnesan AP, Prasad RN. Papaya (Carica papaya) consumption is unsafe in pregnancy: Fact or fable? Scientific evaluation of a common belief in some parts of Asia using a rat model. Br J Nutr 2002;88:199-203.

5. Russell W, Burch RL. The Principles of Humane Experimental Technique. Vol. 1. London, UK: Methuen Press; 1959. p. 10-32.

6. Fan Y, Cheng M, Cheng Y. The reformation in our organic chemistry classes caused by the excellent software ACD/ChemSketch. J Guangzhou Univ 2002;6:G434.

7. Walters WP, Murcko MA. Prediction of drug-likeness. Adv Drug Deliv Rev 2002;54:255-71

8. Clark DE, Pickett SD. Computational methods for the prediction of drug-likeness. Drug Discov Today 2000;5:49-58.

9. Srivastava AK, Singh VK. Carica Papaya-a herbal medicine. Int J Res Stud Biosci 2016;4:19-25.

10. Roshan A, Verma NK, Gupta A. A brief study on Carica Papaya-a review. Int J Curr Trends Pharm Res 2014;2:541-50.

11. Manohar PR. Papaya, dengue fever and ayurveda. Anc Sci Life 2013;32:131-3.

12. Senthilvel P, Lavanya P, Kumar KM, Swetha R, Anitha P, Bag S, et al. Flavonoid from Carica papaya inhibits NS2B-NS3 protease and prevents dengue 2 viral assembly. Bioinformation 2013;9:889-95.

13. Subenthiran S, Choon TC, Cheong KC, Thayan R, Teck MB Muniandy PK, et al. Carica papaya leaves juice significantly accelerates the rate of increase in platelet count among patients with dengue fever and dengue haemorrhagic fever. Evid Based Complement Alternat Med 2013;2013:616737. 